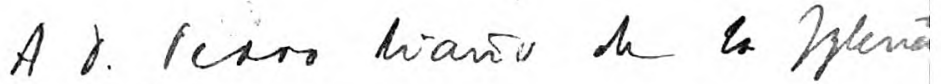 homenari he aunsir
}

Camille Pitollet Pans if \& Juha 1908 c. Fitome

LES

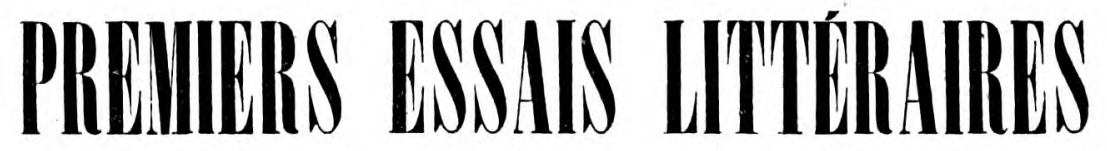

DE FERNÁN CABALLERO.

\section{DOCUMENTS INÉDITS}

Extrait du BULLETIN HISPANIQUE

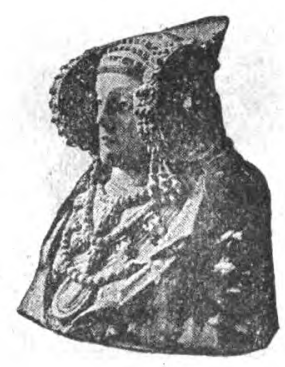

Bordeaux :

FERET \& FILS, ÉDITEURS, I5, GOURS DE L'INTENDANCE

Lyon: Henri GEORG, 36-42, passage de L'Hòtel-Dieu

Marseille: Paul RUAT, 54, rue Paradis | Montpellier: C. COUlet, 5, Grand'Rue

Toulouse: Édouard PRIVAT, I4, rUE dES ARTs Madrid : MURILlO, Alcalí, 7

Paris :

Albert fontemoing, 4, rue Le Goft

Alphonse piCard \& Fils, 82, rue Bonaparte 